\title{
Fusible, Elastic, and Biodegradable Polyesters of 2-Pyrone-4,6-Dicarboxylic Acid (PDC)
}

\author{
By Tsuyoshi Michinobu,${ }^{1,2, \dagger}$ Masami Bito, ${ }^{1}$ Yoshiko YAMAdA, ${ }^{1}$ Miki TanimuRA,${ }^{1}$ Yoshihiro KataYAma ${ }^{3}$ \\ Eiji MASAI, ${ }^{4}$ Masaya NAKAMURA, ${ }^{5}$ Yuichiro OTSUKA,${ }^{5}$ Seiji OHARA,${ }^{5}$ and Kiyotaka SHIGEHARA ${ }^{1,2, *}$
}

2-Pyrone-4,6-dicarboxylic acid (PDC), a chemically stable metabolic intermediate of lignin, 1,4-butanediol, and succinic anhydride were polymerized in the presence of an appropriate catalyst, such as $\mathrm{Sb}_{2} \mathrm{O}_{3}, \mathrm{TiO}(\mathrm{acac})_{2}$, and $\mathrm{CH}_{3} \mathrm{SO}_{3} \mathrm{H}$, to afford the corresponding polyesters. The molecular weight $\left(M_{\mathrm{n}}\right)$ of the polyesters exceeded 10,000, but they were soluble in the common organic solvents when the PDC feed ratio was $<10 \mathrm{~mol} \%$. Furthermore, the polyesters showed well-defined melting points ranging from 82 to $107^{\circ} \mathrm{C}$ and, consequently, the fusibility was realized for the first time for the PDC polymers. Films of these PDC polyesters lacked sufficient mechanical strength, but blended films with poly(L-lactic acid) were found to improve the elastic features. The degradation behaviors of the PDC polyesters were investigated by the biodegradability test or the accelerated hydrolysis tests. Comparison between the obtained PDC polyester and poly(butylene succinate) revealed a remarkable increase in the biodegradability by copolymerization with PDC.

KEY WORDS: Biomass-Based Polymer / Biodegradability / Lignin / Mechanical Strength / Polyester /

Biomass-based polymers have attracted much attention as sustainable alternatives to petrochemicals. ${ }^{1-11}$ Among the many natural carbon resources for preparation of such polymers, we noted that lignin is one of the most promising carbon resources because it is abundant in nature. ${ }^{12}$ However, lignin has not yet been successfully integrated into industrial manufacturing processes. Previously, we established the preparation protocol of a novel dibasic acid, 2-pyrone-4,6-dicarboxylic acid (PDC), on a large scale from the lignin-bio-metabolic intermediates by transformed bacterium. ${ }^{13}$ PDC is composed of a pseudoaromatic ring system with two carboxylic acids and features a well-defined UV absorption and solvatochromic emission, ${ }^{14}$ strong affinity to metal ions, and anti-bacterial action. ${ }^{15}$ Taking into account the fact that the chemical structure of PDC is similar to isophthalic acid except for the polar pseudo-aromatic ring, we could successfully synthesize the PDC polyesters by polycondensation with $\alpha, \omega$-alkylenediol or bis(2-hydroxyethyl)terephthalate ${ }^{16,17}$ or by using the copper(I)-catalyzed azide-alkyne click reaction. ${ }^{18}$ A series of these studies revealed that increasing the PDC proportion in the polymers improves their thermal properties, e.g., decomposition temperature $>210{ }^{\circ} \mathrm{C}$, but at the same time, loses the advantageous properties of aliphatic polymers, such as fusibility, elasticity, and high solubility in organic solvents. Thus, the obtained low molecular weight PDC polymers (or oligomers) became infusible and, accordingly, were difficult to process.

Poly(alkylene succinate)s are regarded as an important candidate of future green plastics in industry that show an excellent elasticity and processability as well as a good biodegradability. ${ }^{19-21}$ The high molecular weight polymers can be readily obtained by the efficient condensation reaction between $\alpha, \omega$-alkylenediol and succinic anhydride. To enhance the thermal and mechanical properties of these polymers, two main approaches have generally been proposed. One is the composite preparation with high-strength fillers, leading to reinforced plastics. ${ }^{21}$ The other is incorporation of rigid aromatic components, such as a benzene ring, into the polymer structures by copolymerization. The latter approach is an efficient method for intrinsically improving the material properties and allows us to quantitatively evaluate the polymer structure-property relationship. Therefore, combined with the pseudo-aromatic ring system of PDC obtained from the purely biomass-based resource, we decided to prepare a novel class of poly(alkylene succinate) copolymers with the required thermal and mechanical properties. We now describe the successful incorporation of PDC into poly(butylene succinate) (PBS) by copolymerization and also report the expected high thermal and mechanical properties as well as the inherent good solubility in organic solvents and excellent degradation behavior.

\section{EXPERIMENTAL}

\section{Materials}

All reagents were obtained from Kanto Chemical Co., Wako Chemical Industries Ltd., and Tokyo Kasei Co., unless otherwise stated and used without further purification. 2Pyrone-4,6-dicarboxylic acid (PDC) was prepared from proto-

\footnotetext{
${ }^{1}$ Graduate School of Engineering, Tokyo University of Agriculture and Technology, Koganei 184-8588, Japan

${ }^{2}$ Institute of Symbiotic Science and Technology, Tokyo University of Agriculture and Technology, Koganei 184-8588, Japan

${ }^{3}$ Graduate School of Bio-Applications and Systems Engineering, Tokyo University of Agriculture and Technology, Koganei 184-8588, Japan

${ }^{4}$ Department of Bioengineering, Nagaoka University of Technology, Nagaoka 940-2188, Japan

${ }^{5}$ Forestry and Forest Products Research Institute, Tsukuba 305-8687, Japan

Present address: Global Edge Institute, Tokyo Institute of Technology, Ookayama, Meguro-ku, Tokyo 152-8550, Japan

*To whom correspondence should be addressed (Tel: +81-42-388-7052, Fax: +81-42-381-8175, E-mail: jun@cc.tuat.ac.jp).
} 
catechuate via the metabolic pathway of Sphingomonas paucimobilis SYK-6 as reported previously. ${ }^{13}$

\section{Polymerization}

PDC copolymers were prepared by the direct polycondensation of 1,4-butanediol (1,4-BD), succinic anhydride (SA), and 2-pyrone-4,6-dicarboxylic acid (PDC) in the presence of $\mathrm{Sb}_{2} \mathrm{O}_{3}, \mathrm{TiO}(\mathrm{acac})_{2}$, or methanesulfonic acid as a catalyst. A mixture of three monomers and a catalyst was charged in a round-bottle flask, was vigorously stirred at $170^{\circ} \mathrm{C}$ under $\mathrm{N}_{2}$ for $5 \mathrm{~h}$, followed by at $170^{\circ} \mathrm{C}$ at $5 \mathrm{mmHg}$ for $17 \mathrm{~h}$ and then at $120^{\circ} \mathrm{C}$ at $5 \mathrm{mmHg}$ for $17 \mathrm{~h}$. After cooling to room temperature, chloroform was added to the reaction mixture and poured into methanol. The precipitates were collected and the chloroform soluble fraction was purified by reprecipitation into methanol. The polymerization yields, calculated from the soluble fraction and a small amount of the insoluble gel, are ca. $90 \%$.

${ }^{1} \mathrm{H}$ NMR $\left(300 \mathrm{MHz}, \mathrm{CDCl}_{3}\right): \delta=1.70\left(s,-\mathrm{CH}_{2}-\right), 2.66(s$, $\left.-\mathrm{C}(=\mathrm{O}) \mathrm{CH}_{2}-\right), 4.11\left(s,-\mathrm{CH}_{2}-\right), 7.12(s$, pyrone $\varepsilon \mathrm{H}), 7.50 \mathrm{ppm}$ $(s$, pyrone $\gamma \mathrm{H}) ;{ }^{13} \mathrm{C} \mathrm{NMR}\left(75 \mathrm{MHz}, \mathrm{CDCl}_{3}\right): \delta=25.20$ $\left(-\mathrm{OCH}_{2} \underline{\mathrm{CH}}_{2}-\right), 28.66\left(-\mathrm{C}(=\mathrm{O}) \underline{C H}_{2}-\right), 63.96\left(-\mathrm{OCH}_{2} \mathrm{CH}_{2}-\right)$, 108.23 (pyrone $\varepsilon \mathrm{C}$ ), 122.55 (pyrone $\gamma \mathrm{C}$ ), 143.03 (pyrone $\delta \mathrm{C}$ ), 149.59 (pyrone $\phi \mathrm{C}), \quad 158.98 \quad$ (pyrone $\delta \mathrm{C}-\underline{\mathrm{C}}(=\mathrm{O})), \quad 162.33$ (pyrone $\beta \mathrm{C}), 171.97\left(-\underline{\mathrm{C}}(=\mathrm{O}) \mathrm{CH}_{2}-\right.$ ).

\section{General Measurements}

${ }^{1} \mathrm{H}$ NMR and ${ }^{13} \mathrm{C}$ NMR spectra were measured on a JEOL model AL300 spectrometer at $20^{\circ} \mathrm{C}$. Chemical shifts are reported in ppm downfield from $\mathrm{SiMe}_{4}$, using the solvent's residual signal as an internal reference. Number average molecular weight $\left(M_{\mathrm{n}}\right)$ of the polymers was estimated by a JASCO 980 gel permeation chromatography (GPC) equipped with polystyrene gel columns using chloroform as an eluent at a flow rate of $1.0 \mathrm{~mL} \mathrm{~min}^{-1}$ after calibration with standard polystyrene. Thermogravimetric-differential thermal analysis (TG-DTA) was carried out on a Rigaku Thermoplus TG 8120 under nitrogen flow at a heating rate of $10^{\circ} \mathrm{C} \mathrm{min}^{-1}$ from 20 to $1000^{\circ} \mathrm{C}$. Elemental analyses of the polymers were carried out on a Yanaco MT-5 elemental analyzer. Strain-stress (S-S) curves of the polymer films, prepared by hot press of the PDC polymers at $130{ }^{\circ} \mathrm{C}$ at $0 \mathrm{MPa}$ for $5 \mathrm{~min}$, followed by at $130^{\circ} \mathrm{C}$ at $2 \mathrm{MPa}$ for $5 \mathrm{~min}$, or by slow evaporation of the chloroform solution of a mixture of the PDC polymer and poly(L-lactic acid) (Unitika Co. Ltd., Terramac ${ }^{\circledR}, M_{\mathrm{n}}=1.74 \times 10^{5}$ with Lcontent of $>98 \%$ ) on a glass substrate in vacuo, were measured at $21 \pm 2{ }^{\circ} \mathrm{C}$ in an atmosphere of dry nitrogen by using a Tensilon testing machine (Auto COM/AC-50A, TS Engineering Co.). Young's moduli were estimated from the initial (less than $0.5 \%$ elongation) slopes of $\mathrm{S}-\mathrm{S}$ curves.

\section{Evaluation of Polymer Biodegradability}

The PDC polymer powder was pressed at $130^{\circ} \mathrm{C}$ at $0 \mathrm{MPa}$ for $5 \mathrm{~min}$, followed by at $130^{\circ} \mathrm{C}$ at $2 \mathrm{MPa}$ for $5 \mathrm{~min}$, yielding $2.0 \mathrm{~mm} \phi \times 3.0 \mathrm{~mm}$ pellets. According to ISO $14855-2$ testing, the biodegradability of $1 \mathrm{~g}$ of the pellet at $59.5^{\circ} \mathrm{C}$ in an active compost obtained from Kanagawa prefecture recycle center, Japan, was estimated by monitoring $\mathrm{CO}_{2}$ evolved.

$$
\begin{aligned}
& \text { Biodegradability }(\%) \\
& \quad=100 \times\left|\Sigma\left(\mathrm{CO}_{2}\right)_{\mathrm{T}}-\Sigma\left(\mathrm{CO}_{2}\right)_{\mathrm{B}}\right| /\left(\mathrm{CO}_{2}\right)_{\mathrm{Th}}
\end{aligned}
$$

Here, $\Sigma\left(\mathrm{CO}_{2}\right)_{\mathrm{T}}$ is the amount of $\mathrm{CO}_{2}$ evolved from the test samples between the start and time $t, \Sigma\left(\mathrm{CO}_{2}\right)_{\mathrm{B}}$ is the amount of $\mathrm{CO}_{2}$ evolved from the blank test bottle between the start and time $t$, and $\left(\mathrm{CO}_{2}\right)_{\mathrm{Th}}$ is the theoretical amount of $\mathrm{CO}_{2}$ evolved from the test sample assuming that all carbons of the test samples are transformed into $\mathrm{CO}_{2}$.

\section{Hydrolysis Test of Film Samples}

The $0.3 \mathrm{~mm}$-thick polymer films prepared by the hot press were cut into about $100 \mathrm{mg}$ test pieces and were subjected to the accelerated hydrolysis tests in $50 \mathrm{~mL}$ of $0.10 \mathrm{M} \mathrm{NaOH}$ solution at $40^{\circ} \mathrm{C}$ or $0.05 \mathrm{M}$ aq. $\mathrm{H}_{2} \mathrm{SO}_{4}$ at $40^{\circ} \mathrm{C}$ without agitation. After the given periods, the remaining portions of the film samples were collected by filtration, washed with distilled water, and then dried at $100{ }^{\circ} \mathrm{C}$ in vacuo. The weight loss of the samples was calculated as the remaining weight relative to the initial weight. Polymer fragments solubilized in the solutions were attempted to collect by evaporating the aqueous solution after the dialysis through a $24 \AA$-pore cellophane membrane.

\section{RESULTS AND DISCUSSION}

\section{Polymer Synthesis and Characterization}

Polyesters of 1,4-butanediol (1,4-BD), succinic anhydride (SA), and 2-pyrone-4,6-dicarboxylic acid (PDC) were prepared by the conventional polycondensation in the presence of an appropriate acid catalyst (Scheme 1). The obtained polyesters are symbolized as BSP. Previously, we reported the preparation of the soluble oligoesters of PDC by polycondensation between PDC and $\alpha, \omega$-alkylenediol or bis(2-hydroxyethyl)terephthalate in the presence of $\mathrm{Sb}_{2} \mathrm{O}_{3}$ as a catalyst, since $\mathrm{Sb}_{2} \mathrm{O}_{3}$ is the frequently employed catalyst for polyester synthesis in industry, e.g., the manufacture of poly(ethylene terephthalate), PET. ${ }^{22}$ However, the corresponding polyesters prepared by the post-polymerization of the oligoesters became insoluble probably because of the strong intermolecular interactions
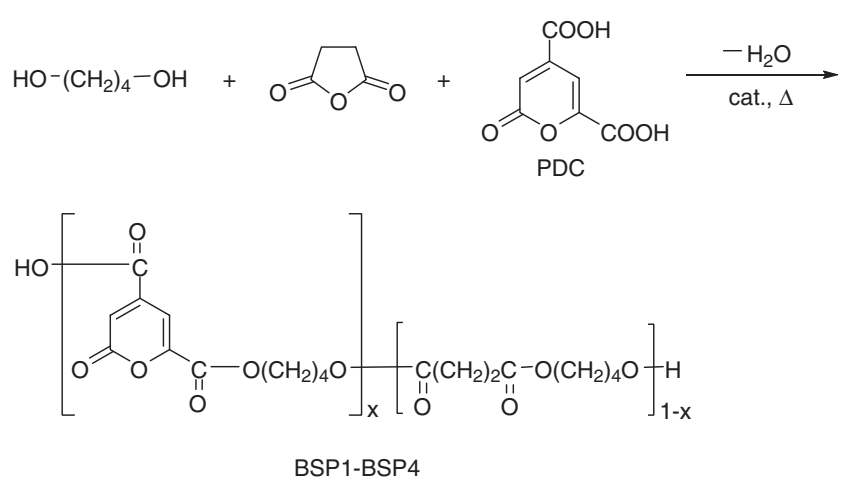

Scheme 1. 
Table I. Polymerization results ${ }^{a}$

\begin{tabular}{|c|c|c|c|c|c|c|}
\hline \multirow{2}{*}{ Run } & \multirow{2}{*}{ Polymer } & Feed mol ratio & \multirow{2}{*}{ Catalyst (mol\%) } & \multirow{2}{*}{$M_{\mathrm{n}}^{\mathrm{b}}$} & \multirow{2}{*}{$\begin{array}{l}\text { Dec. temp } \\
\left({ }^{\circ} \mathrm{C}\right)^{\mathrm{c}}\end{array}$} & \multirow{2}{*}{$\begin{array}{l}\text { m.p. } \\
\left({ }^{\circ} \mathrm{C}\right)^{\circ}\end{array}$} \\
\hline & & 1,4-BD/SA/PDC & & & & \\
\hline 1 & BSP1 & $10 / 9 / 1$ & $\mathrm{Sb}_{2} \mathrm{O}_{3}(0.011)$ & 16000 & 359 & 107 \\
\hline 2 & BSP2 & $5 / 4 / 1$ & $\mathrm{Sb}_{2} \mathrm{O}_{3}(0.023)$ & 11000 & 323 & 92 \\
\hline 3 & BSP3 & $5 / 4 / 1$ & $\mathrm{TiO}(\mathrm{acac})_{2}(0.011)$ & 10000 & 360 & 85 \\
\hline 4 & BSP4 & $5 / 4 / 1$ & $\mathrm{CH}_{3} \mathrm{SO}_{3} \mathrm{H}^{\mathrm{e}}$ & 15000 & 344 & 82 \\
\hline
\end{tabular}

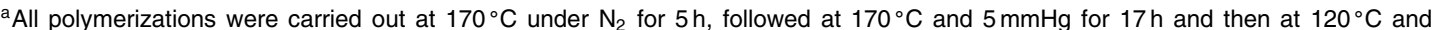
$5 \mathrm{mmHg}$ for $17 \mathrm{~h}$. ${ }^{b}$ Determined by GPC (polystyrene standard, $\mathrm{CHCl}_{3}$ eluent). ${ }^{\mathrm{c}}$ Determined by thermogravimetric analysis. ${ }^{\mathrm{d} D e t e r m i n e d}$ by differential thermal analysis. ${ }^{e}$ Catalyst amount could not be accurately weighed.

between the PDC moieties when the molecular weight exceeded about 4,000. Therefore, other catalysts to improve the polymerization efficiency of PDC were not pursued. In this study, soluble and high molecular weight PDC polyesters were targeted and, therefore, the PDC content in the polymers was reduced to $<10 \mathrm{~mol} \%$. Three different catalysts were examined under the polymerization conditions similar to the previous methods and the catalyst efficiency was qualitatively judged from the number average molecular weight $\left(M_{\mathrm{n}}\right)$ of the polyesters determined by GPC (Table I). ${ }^{23}$ The monomer feed ratio of the hydroxyl group and carboxylic acid group always remained equivalent. First, the polycondensation of 1,4-BD, SA, and PDC at the monomer feed ratio of 10:9:1 in the presence of $\mathrm{Sb}_{2} \mathrm{O}_{3}$ as a catalyst was performed at $170{ }^{\circ} \mathrm{C}$ under nitrogen for $5 \mathrm{~h}$, then at the same temperature under vacuum $(5 \mathrm{mmHg})$ for $17 \mathrm{~h}$ followed by cooling to $120^{\circ} \mathrm{C}$ for $17 \mathrm{~h}$. Noticeably, the resulting polyester BSP1 was soluble in common organic solvents, such as THF, $\mathrm{CHCl}_{3}$, and $\mathrm{DMF}$, ensuring the $M_{\mathrm{n}}$ value as a good guide for evaluation of the polymerization conditions. The $M_{\mathrm{n}}$ of BSP1 determined by GPC using a $\mathrm{CHCl}_{3}$ eluent was 16,000 (Run 1). Incorporation of a higher amount of PDC is desired in order to enhance the thermal and mechanical properties of the polyesters. Therefore, the monomer feed ratio was changed to $1,4-\mathrm{BD} / \mathrm{SA} / \mathrm{PDC}=$ $5: 4: 1$. However, an increase in the PDC feed ratio from 5 to $10 \mathrm{~mol} \%$ resulted in a decrease of the $M_{\mathrm{n}}$ value $(11,000)$, although a double amount of the catalyst was employed (Run 2; BPS2). Other catalysts were also examined. The use of $\mathrm{TiO}(\mathrm{acac})_{2}$ in place of $\mathrm{Sb}_{2} \mathrm{O}_{3}$ did not increase the $M_{\mathrm{n}}$ value $(10,000)$ of the polyester, suggesting the inferior activity of this catalyst (Run 3; BPS3). On the other hand, the $\mathrm{CH}_{3} \mathrm{SO}_{3} \mathrm{H}$ catalyst could fairly improve the $M_{\mathrm{n}}$ value $(15,000)$ (Run 4; BPS4), but significant problems included the accurate determination of the catalyst amount when the reaction scale is small and discoloration of the resulting polymer occurs. Thus, it is concluded that $\mathrm{Sb}_{2} \mathrm{O}_{3}$ is the most appropriate catalyst investigated so far for preparation of PDC polyesters and, therefore, we employed the polyesters, BSP1 and BPS2, for the following investigation on the mechanical and degradable properties (vide infra).

${ }^{1} \mathrm{H}$ NMR spectra of the polyesters were measured in $\mathrm{CDCl}_{3}$ at $20{ }^{\circ} \mathrm{C}$. In addition to the typical peaks of poly(butylene succinate) at the higher magnetic field, two weak single peaks ascribed to the pyrone ring were observed in the aromatic region (Figure 1). Careful integration and comparison of the (a)

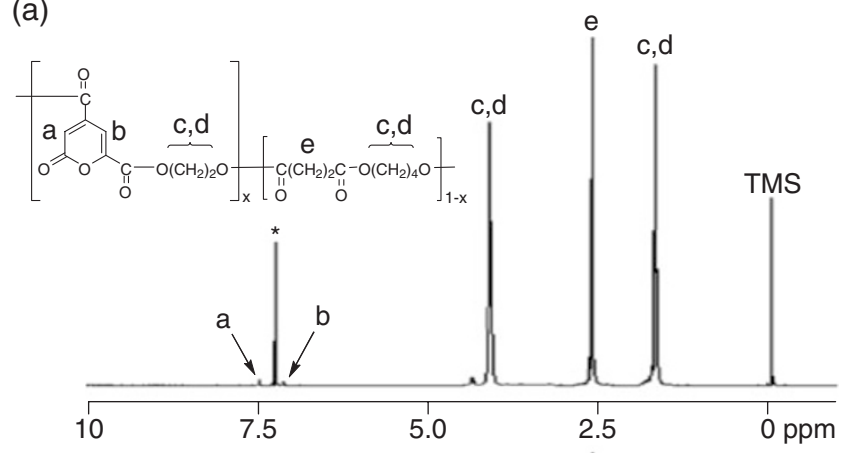

(b)

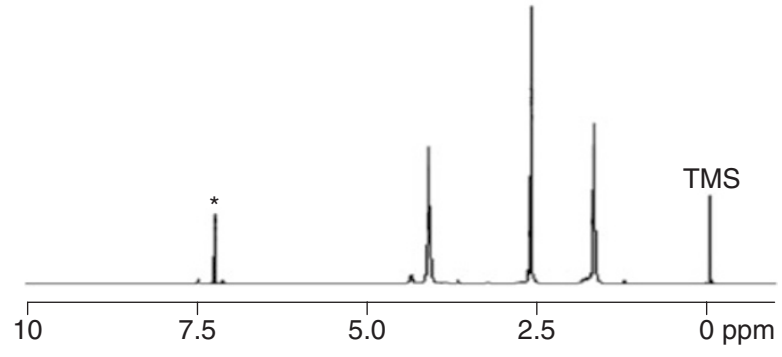

Figure 1. ${ }^{1} \mathrm{H}$ NMR spectra of (a) BSP1 and (b) BSP2 in $\mathrm{CDCl}_{3}$ at $20^{\circ} \mathrm{C}$. The residual solvent peak is marked.

peak areas revealed that the PDC contents in BSP1 and BSP2 were $1.0 \mathrm{~mol} \%$ and $3.0 \mathrm{~mol} \%$, respectively. Elemental analysis of the polyesters also supported this result. The PDC content in $\mathrm{BSP} 1$, calculated from the $55.2 \% \mathrm{C}$ and $6.8 \% \mathrm{H}$ contents, was $1.4 \mathrm{~mol} \%$. Similarly, the $\mathrm{C}$ and $\mathrm{H}$ contents of BPS2 were $54.6 \%$ and $6.6 \%$, respectively, which corresponds to $2.9 \mathrm{~mol} \%$ of the PDC content in BPS2. The values determined from the ${ }^{1} \mathrm{H}$ NMR and elemental analyses showed fairly good agreement, and these reliable results suggest that the polymerization capability of PDC is definitely lower than that of succinic acid when considering the monomer feed amount (PDC content: $5 \mathrm{~mol} \%$ for BSP1 and $10 \mathrm{~mol} \%$ for BSP2). Accordingly, the monomer composition (1,4-BD/SA/PDC) of BSP1 and BSP2, determined by the elemental analyses, was $36 / 35 / 1$ and $17 /$ $16 / 1$, respectively.

The thermal properties of the obtained polymers were investigated by thermogravimetric-differential thermal analysis (TG-DTA) at the heating rate of $10^{\circ} \mathrm{C} \mathrm{min}^{-1}$ in a nitrogen atmosphere (Figure 2). Decomposition of the PDC polyesters usually starts at about $250^{\circ} \mathrm{C}$, reflecting the decomposition temperature of PDC at $253{ }^{\circ} \mathrm{C} .{ }^{14}$ However, in this case, the decomposition temperatures determined by derivative ther- 

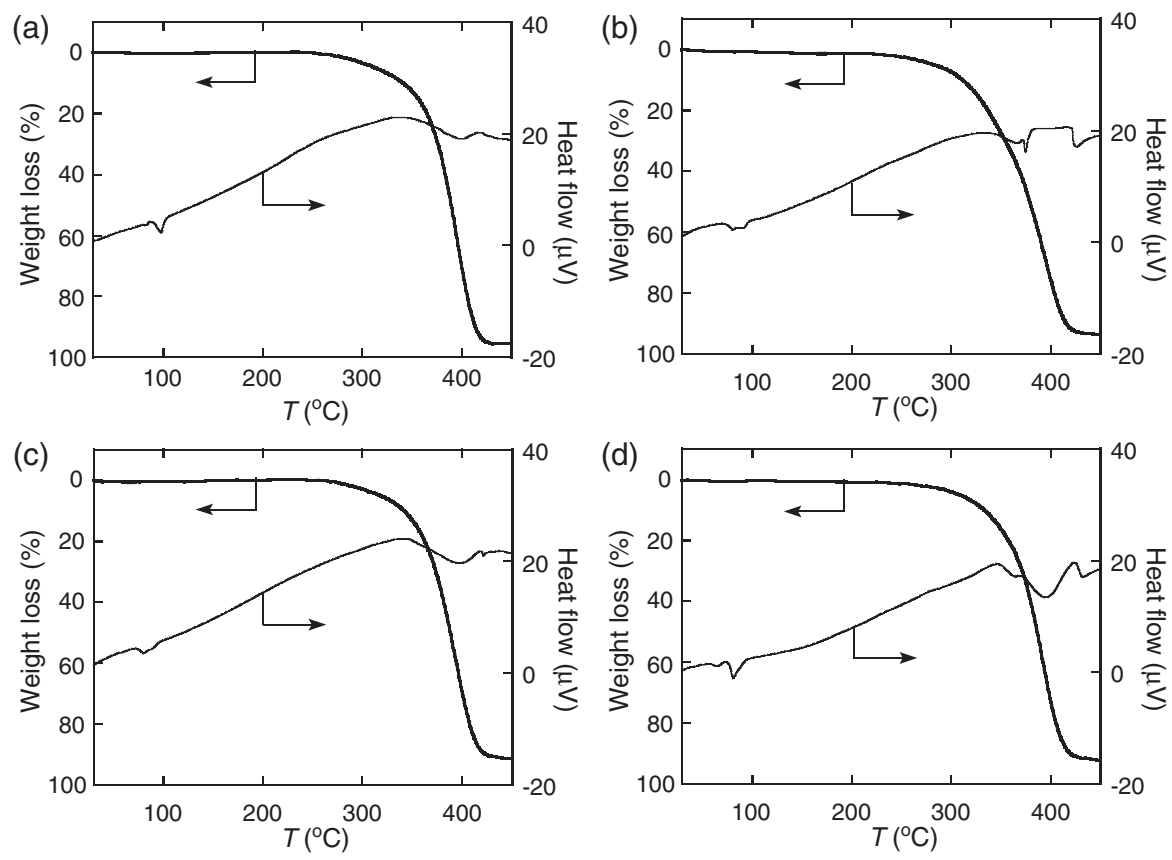

Figure 2. Thermogravimetric-differential thermal analysis of (a) BSP1, (b) BSP2, (c) BSP3, and (d) BSP4.

mogravimetry ranged from 323 to $360^{\circ} \mathrm{C}$. It should be noted that no noticeable weight loss was observed at about $250^{\circ} \mathrm{C}$, albeit the low PDC content $(<3.0 \mathrm{~mol} \%)$ in the polyesters. The previously prepared PDC polyesters were insoluble, infusible, and hard solids that cannot be processed into thin films or textiles. ${ }^{15-18}$ For example, the copolymers of PDC and bis(2hydroxyethyl)terephthalate (BHT) were infusible even when the PDC content was as low as $10 \mathrm{~mol} \%$. Furthermore, the PDC polymers prepared by the $\mathrm{Cu}(\mathrm{I})$-catalyzed azide-alkyne click reaction have high $M_{\mathrm{n}}$ values of $>10^{4}$, but they did not show any thermal transitions in the temperature range up to $150^{\circ} \mathrm{C}$. In sharp contrast to these examples, all the BSP polyesters displayed well-defined melting points ranging from 82 to $107^{\circ} \mathrm{C}$ determined by differential thermal analysis. These values correspond to the melting points of the poly(butylene succinate)s, indicating that PDC does not significantly contribute to the thermal properties of the BSP polyesters.

\section{Mechanical Strength Measurements}

Taking into account the fusible feature of the BSP polyesters, the films of BSP1 and BSP2 were prepared by hot pressing at $130{ }^{\circ} \mathrm{C}$ in vacuo for $5 \mathrm{~min}$, then at $2 \mathrm{MPa}$ for $5 \mathrm{~min}$. They were next subjected to the strain-stress (S-S) measurements using a Tensilon testing machine in dry nitrogen at $21 \pm 2{ }^{\circ} \mathrm{C}$. Although the sample blades with a size of $5 \times 20 \mathrm{~mm}$ were successfully obtained, BPS1 was unfortunately too brittle to be measured. Measurements of the BPS2 were possible, but the maximum fracture stress was disappointedly low (Table II).

To improve these poor mechanical properties of the BSP polyesters, the blended films with poly(L-lactic acid) (PLLA), that is representative of the rigid biodegradable polymers, were prepared by slow evaporation of a $\mathrm{CHCl}_{3}$ solution on a glass
Table II. Mechanical properties of the polyester samples

\begin{tabular}{cccc}
\hline Sample & $\begin{array}{c}\text { Maximum fracture } \\
\text { elongation }(\%)^{\mathrm{a}}\end{array}$ & $\begin{array}{c}\text { Maximum fracture } \\
\text { stress }(\mathrm{MPa})\end{array}$ & $\begin{array}{c}\text { Young's modulus } \\
(\mathrm{MPa})\end{array}$ \\
\hline BSP1 & - & - & - \\
BSP2 & 0.5 & 2.2 & 5.0 \\
BSP1+PLLA $^{\text {b }}$ & 73.0 & 27.3 & 24.1 \\
BSP2+PLLA $^{\text {b }}$ & 90.6 & 36.8 & 34.0 \\
\hline
\end{tabular}

anitial sample length is $10 \mathrm{~mm}$. ${ }^{\mathrm{b}} 10 \mathrm{wt} \% \mathrm{BSP}$ was mixed with PLLA (Unitika Co. Ltd., Terramac ${ }^{\circledR}$ ).

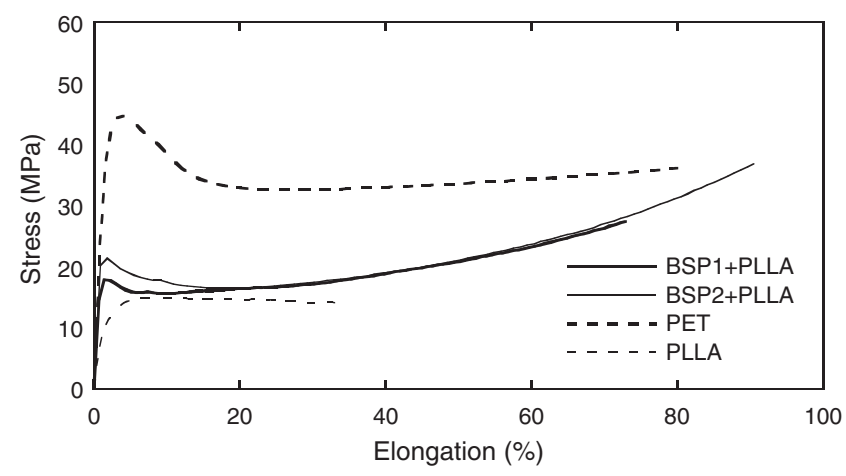

Figure 3. Strain-stress curves of the polyesters at $21 \pm 2{ }^{\circ} \mathrm{C}$ in air.

substrate. When $10 \mathrm{wt} \%$ of the BSP polyesters was mixed with PLLA, sufficiently strong films were obtained and again subjected to the S-S measurements. The S-S curves of the blend films are shown in Figure 3 and the results of the PLLA and poly(ethylene terephthalate) (PET) films prepared and measured under the same conditions are also included for comparison. PLLA itself exhibited a breakdown at the strain of $34 \%$ with the almost constant stress of about $14 \mathrm{MPa}$ and did 


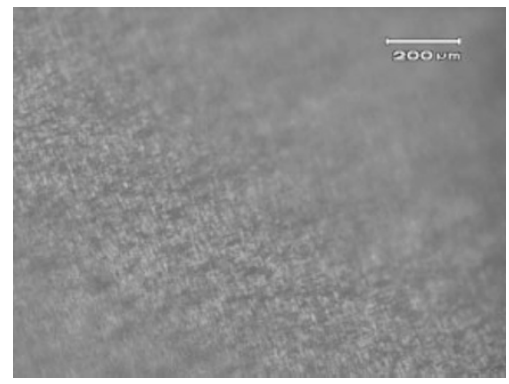

Figure 4. Optical microscopy image of the BSP1+PLLA sample after the tensile tests.

not display any yield points. Remarkably, the addition of BSP polyesters to PLLA dramatically increased the elastic features. The sample blades of the blend films showed clear yield points at the strain of about $1.5 \%$ with the maximum stress of $18 \mathrm{MPa}$ for BSP1+PLLA and $21 \mathrm{MPa}$ for BSP2+PLLA. Beyond the yield points, these samples showed a further ductility up to the strain of about $73 \%$ for BSP1+PLLA and about $91 \%$ for BSP2+PLLA with the gradual increase in the stress values. In the case of the $10 \mathrm{wt} \%$ addition of BSP1, the maximum stress at the break point reached $27.3 \mathrm{MPa}$, whereas the $10 \mathrm{wt} \%$ addition of BSP2 displayed the maximum stress of $36.8 \mathrm{MPa}$. The latter value is almost comparable to the tensile stress at the break point of PET. ${ }^{24}$ These results suggest that the blended films of BSP and PLLA possess sufficient viscoelastic properties so that they are not fractured by partial elongation. ${ }^{25}$ It should be noted that the blend films of PBS and PLLA show the similar tensile properties. ${ }^{26}$ The blend film at a composition of $10 \mathrm{wt} \%$ PBS and $90 \mathrm{wt} \%$ PLLA exhibited considerably higher elongation at break than pure PBS and PLLA.

However, our PBS-based additive polymer, namely BSP, contains PDC moieties. Optical microscopy images of the blend films of BSP1 after the tensile measurements demonstrated the partial orientation of the polymer chains, which was not revealed in the previous report ${ }^{26}$ (Figure 4). Since these mechanical properties are associated with the polymer crystallinity, the PDC content in the BSP polyesters can contribute to their control. Young's moduli of the films were roughly estimated from the initial slopes of the S-S curves of Figure 3 and the data are summarized in Table II. The rigid nature of the blended films was again characterized by their higher Young's modulus when compared to the films with the single component BSP polyester. The blended film of BSP2 was more rigid than that of BSP1, implying the crystalline feature of the PDC moieties due to the strong intermolecular interactions.

\section{Degradability Tests}

It is known that the PDC ring can be degraded into two kinds of $\alpha$-ketocarboxylic acids, 2-oxopropionic acid (pyruvic acid) and 2-oxobutanedioic acid (oxalacetic acid), via hydrolyzed intermediates in the biometabolic system. ${ }^{13}$ It was previously found from the biodegradability test and accelerated hydrolysis tests that this degradation of the PDC ring also takes place when it is incorporated into the polymer main chains. ${ }^{16}$

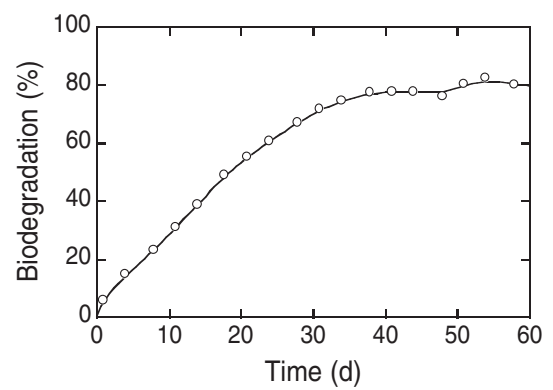

Figure 5. Representative biodegradation behavior of BSP1 measured according to ISP14855-2 testing.

To investigate the degradable behaviors of the new PDC polymers, the biodegradability was evaluated according to the standard ISO method and the hydrolysis tests were performed in both acidic and basic aqueous solutions.

Poly(butylene succinate) is known as a slowly degrading polymer and the biodegradation behavior was investigated in detail. For example, the powder sample of poly(butylene succinate) displayed a plateau region for about $10 \mathrm{~d}$ and then started a sudden degradation, reaching about $20 \%$ biodegradation after $45 \mathrm{~d} .{ }^{27}$ The biodegradation test of the BSP1 polyester was performed as a pellet sample under comparable conditions and the result is depicted in Figure 5. In contrast to the reported behavior of poly(butylene succinate), the degradation behavior was almost linear for $30 \mathrm{~d}$ and then saturated, reaching about $80 \%$ after $40 \mathrm{~d}$. The degrading efficiency mostly depends on the sample shape or the surface area and, accordingly, powder samples usually show a faster degradation than the film and pellet samples. Considering this general fact, the obtained result demonstrates the dramatic improvement in the biodegradation by incorporation of a small amount of PDC moieties into BSP1 (only $1.0-1.4 \mathrm{~mol} \%$ ).

Figure $6 \mathrm{a}$ and $6 \mathrm{~b}$ illustrate the results of the hydrolysis tests of the BSP polyesters in aqueous $\mathrm{NaOH}$ and $\mathrm{H}_{2} \mathrm{SO}_{4}$ solutions, respectively. Similarly to the previously synthesized PDC polyesters, ${ }^{16}$ the BSP polyesters showed a significant hydrolysis behavior in basic solutions. The hydrolysis tests of BSP1 and BSP2 in a $0.10 \mathrm{M}$ aqueous $\mathrm{NaOH}$ solution were completed within 6 and $10 \mathrm{~h}$, respectively. These are the fastest solubilizations of the PDC polymers reported so far, because poly(butylene succinate) itself can also be hydrolyzed in a basic solutions. Taking into account the PDC content in the BSP polyesters, poly(butylene succinate) has a higher degradation ability than the PDC moiety under basic conditions. In contrast, the acid hydrolysis behaviors were much slower and independent of the PDC content. After $40 \mathrm{~d}$ in a $0.05 \mathrm{M}$ aqueous $\mathrm{H}_{2} \mathrm{SO}_{4}$ solution, the weight loss reached the moderate value of $55 \%$.

\section{CONCLUSION}

New PDC polyesters (BSP) were successfully prepared by polycondensation between 1,4-butanediol, succinic acid, and PDC. Optimization of the polymerization conditions was 
(a)

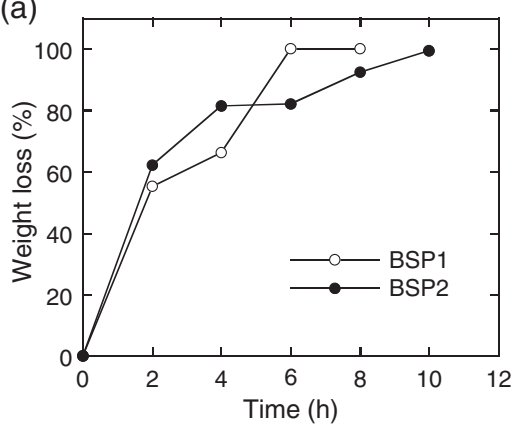

(b)

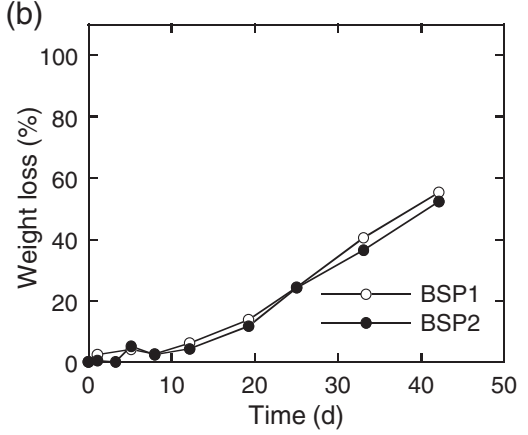

Figure 6. Weight loss of the polyesters upon hydrolysis at $40^{\circ} \mathrm{C}(\mathrm{a})$ in $0.10 \mathrm{M}$ aq. $\mathrm{NaOH}$ and (b) in $0.05 \mathrm{M}_{\text {aq. }} \mathrm{H}_{2} \mathrm{SO}_{4}$.

achieved by variation of the monomer feed ratio and catalyst species. $\mathrm{Sb}_{2} \mathrm{O}_{3}$ was found to be the best catalyst. The obtained polymers possessed the combined features of poly(butylene succinate) and PDC. Thus, fusibility originating from poly(butylene succinate) was for the first time endowed to the PDC polymers, which enabled us to prepare sufficiently strong films by hot pressing. However, since films of the single component BSP polyesters were brittle, the blended films of poly(L-lactic acid) (PLLA) and BSP were prepared by solution casting. The tensile test revealed that they were more rigid and more elastic films than the PLLA film and, at the same time, the maximum stress at the break point was almost comparable to that of the poly(ethylene terephthalate) (PET) film. The biodegradability and accelerated base hydrolysis of the BSP polyesters were significantly high. In particular, the dramatic increase in the biodegradability by copolymerization of a very small amount of PDC was remarkable. Since PDC is a well-defined organic molecule that has never been synthesized from petrochemical sources, further investigations of the copolymers from both bio- and petrochemical sources are worthwhile for future work.

Acknowledgment. This work was supported, in part, by a Grant-in-Aid for Scientific Research from the Ministry of Education, Science, Sports and Culture, Japan, and General Sekiyu Research Promotion. We thank Prof. S. Kajita (Tokyo University of Agriculture and Technology) for useful discussion.

Received: July 9, 2009

Accepted: August 19, 2009

Published: October 9, 2009

\section{REFERENCES AND NOTES}

1. "Biopolymers," A. Steinbuchel, Y. Doi, and M. Hofrichter, Ed., Wiley-VCH, Weinheim, 2002, Vol. 3.

2. B. Kamm, P. R. Gruber, and M. Kamm, "Biorefineries-Industrial Processes and Products," Wiley-VCH, Weinheim, 2006.

3. T. Iwata and Y. Doi, Macromol. Chem. Phys., 200, 2429 (1999).
4. Y. He, T. Masuda, A. Cao, N. Yoshie, Y. Doi, and Y. Inoue, Polym. J., 31, 184 (1999).

5. E. T. H. Vink, K. R. Rábago, D. A. Glassner, and P. R. Gruber, Polym. Degrad. Stab., 80, 403 (2003).

6. Y. Watanabe, T. Iwamoto, A. Teramoto, K. Abe, and Y. Ohkoshi, Mater. Trans., 45, 1005 (2004).

7. A. J. Ragauskas, C. K. Williams, B. H. Davison, G. Britovsek, J. Cairney, C. A. Eckert, W. J. Frederick, J. P. Hallett, D. J. Leak, C. L. Liotta, J. R. Mielenz, R. Murphy, R. Templer, and T. Tschaplinski, Science, 311, 484 (2006).

8. S. Matsumura, Adv. Polym. Sci., 194, 95 (2006).

9. Y. Nishio, Adv. Polym. Sci., 205, 97 (2006).

10. C. K. Williams, Chem. Soc. Rev., 36, 1574 (2007).

11. A. Gandini, Macromolecules, 41, 9491 (2008).

12. M. Funaoka, Polym. Int., 47, 277 (1998).

13. Y. Otsuka, M. Nakamura, K. Shigehara, K. Sugimura, E. Masai, S. Ohara, and Y. Katayama, Appl. Microbiol. Biotechnol., 71, 608 (2006).

14. T. Michinobu, M. Bito, Y. Yamada, Y. Katayama, K. Noguchi, E. Masai, M. Nakamura, S. Ohara, and K. Shigehara, Bull. Chem. Soc. Jpn., 80, 2436 (2007).

15. M. Bito, T. Michinobu, Y. Katayama, Y. Otsuka, M. Nakayama, S. Ohara, E. Masai, and K. Shigehara, Trans. Mater. Res. Soc. Jpn., 33, 1165 (2008).

16. T. Michinobu, M. Hishida, M. Sato, Y. Katayama, E. Masai, M. Nakamura, Y. Otsuka, S. Ohara, and K. Shigehara, Polym. J., 40, 68 (2008).

17. M. Hishida, K. Shikinaka, Y. Katayama, S. Kajita, E. Masai, M. Nakamura, Y. Otsuka, S. Ohara, and K. Shigehara, Polym. J., 41, 297 (2009).

18. T. Michinobu, Y. Inazawa, K. Hiraki, Y. Katayama, E. Masai, M. Nakamura, S. Ohara, and K. Shigehara, Chem. Lett., 37, 154 (2008).

19. T. Fujimaki, Polym. Degrad. Stab., 59, 209 (1998).

20. E. K. Kim, J. S. Bae, S. S. Im, B. C. Kim, and Y. K. Han, J. Appl. Polym. Sci., 80, 1388 (2001)

21. D. N. Bikiaris and D. S. Achilias, Polymer, 49, 3677 (2008).

22. H. R. Billica and J. T. Carriel, U. S. Patent, 19556, 2739957.

23. Polydispersity of all the polyesters ranges from 1.4 to 1.8 .

24. For a tensile measurement of PET, see: C. G'Sell, J. M. Hilver, and A. Dahoun, Int. J. Solid Struct., 39, 3857 (2002).

25. T. Michinobu, M. Bito, M. Tanimura, Y. Katayama, E. Masai, M. Nakamura, Y. Otsuka, S. Ohara, and K. Shigehara, Polym. J., in press. doi:10.1295/polymj.PJ2009133

26. M. Shibata, Y. Inoue, and M. Miyoshi, Polymer, 47, 3557 (2006).

27. H. S. Yang, J. S. Yoon, and M. N. Kim, Polym. Degrad. Stab., 87, 131, (2005). 